\title{
Evaluation of Antidiabetic potential and Hypolipidemic activity of Coccinia indica (leaves) in Diabetic Albino rats
}

\author{
Mamata Pochhi \\ Associate Professor, Department of Biochemistry, Shree Shankaracharya Institute of Medical Science, Bhilai, India
}

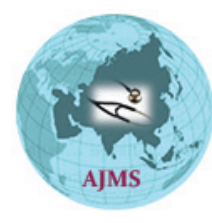

A B S TR A C T

\begin{abstract}
Background: The whole plant of Coccinia indica is very effective in different types of diseases with fewer side effects. The leaves, roots of this plant were claimed to be useful in the treatment of diabetes mellitus based on folk medicine. The purpose of this study was to examine the antihyperglycemic effect of water extract of $\mathrm{C}$. indica in alloxan diabetes rats. Aims and Objectives: The aim of this study is to find whether the conditions, hyperglyclemia and hyerlipidemia, are correlated and whether the application of the aqueous extract leads to abating these two conditions. Materials and Methods: The aqueous leaves extracts of $\mathrm{C}$. indica $(200 \mathrm{mg} / \mathrm{kg}$ ) were administered orally for 14 days, in alloxan induced diabetic rats on Glucose, Lipid profile, Lipoproteins and Lipid metabolizing enzymes activity. Result: The aqueous leaves extract of $\mathrm{C}$. indica induced significant improvement in glucose, serum Lipids, lipoproteins and lipid metabolizing enzyme activity (HMG CoA reductase, LCAT). Conclusion: The present study indicates that the extract of Coccinia indica exhibits lipid lowering, maintaining lipoproteins concentration and also improves the activities of lipid metabolizing enzyme in hyperglycemic rats leading to an increase in peripheral glucose consumption.
\end{abstract}

Access this article online

Website:

http://nepjol.info/index.php/AJMS DOI: 10.3126/ajms.v10i4.24180 E-ISSN: 2091-0576 P-ISSN: 2467-9100

Key words: Coccinia indica; Serum lipids; Lipoproteins; HMG CoA reductase and LCAT

\section{INTRODUCTION}

Diabetes mellitus is a serious metabolic illness worldwide. Defect in the carbohydrate metabolism and continuous efforts of physiological systems to correct this imbalance have been reported to pose overexertion on the endocrine system leading to the deterioration of endocrine control. Variation in carbohydrate metabolic enzymes due to deterioration of endocrine control leads to hyperglycemia ${ }^{1}$ leading to complications that can be acute and long term. ${ }^{2}$

Globally, DM presents enormous and increasingly important public health issues. The prevalence of DM in all age groups was estimated to be $2.8 \%$ (170 million) in 2000 and the rate is expected to rise to $4.4 \%$ (366 million) in $2030 .{ }^{3}$ The worldwide survey on diabetes reveals that among the entire diabetes cases more than $90 \%$ are account to type-II. ${ }^{4}$ The overall death rate in people with diabetes is about twice that of people without diabetes. ${ }^{5}$
At present, most of the diabetes-related research involves drug therapy rather than preventive or nondrug interventions. ${ }^{6}$ In a study, incidence of diabetes was reduced by $58 \%$ with the lifestyle intervention and $31 \%$ by metformin. ${ }^{7}$ Few vegetables that are commonly consumed in India as part of diet have been claimed their anti-diabetic potential especially those from family Cucurbitaceae. As a part of lifestyle modification, dietary intervention focused on consumption of food plants can be an interesting approach in ameliorating the effects of this metabolic disorder to certain extent.

The beneficial uses of medicinal plants in traditional system of medicine of many cultures are extensively documented. Several plants have been used as dietary adjuvant and in treating the number of diseases even without any knowledge on their proper functions and constituents. This practice may be attributed to the uncompromised cost and side effects of synthetic hypoglycemic agents. ${ }^{8}$ Since antique 
era, plants with medicinal properties are enormously used in treating diabetes throughout the world. Many recent scientific investigations have also confirmed the efficacy of plant preparations, few of which are remarkably effective. ${ }^{9}$

Cucurbitaceae is a plant family well known to have about 125 extant genera including 960 species. It is considered to be one of the important families of plants with potent hypoglycemic effects. ${ }^{10}$ In modern drug discovery from medicinal plants, the importance of cucurbitaceae species has been markedly recognized in empirical control of DM.

Coccinia indica Wight. and Arn (Synonym - Cephalandra indica Naud), commonly known as Ivy Gourd or Little gourd belongs to family Cucurbitaceae. It is native of Africa and Asia (India). It is widely distributed as weed in all over India and widely cultivated in large areas. ${ }^{11} \mathrm{It}$ shows presence of various chemical constituents such as alkaloids, carbohydrates, glycosides, phenolic compound, gums, mucilages, triterpenoids, flavonoids, anthraquinones and polysaccharides. ${ }^{12}$ Ayurveda and Unani systems claim C. indica as antidiabetic agent and other traditional uses are anti-inflammatory, antipyretic, analgesic, antimicrobial, antibacterial, antidepressant and expectorant. ${ }^{13-14}$ Sporadic pharmacological studies have supported traditional claims of $\mathrm{C}$. indica in treating diabetes. But most of these studies have employed uncharacterized crude extract of the plant. A scrutiny of literature revealed that no systematic work has been conducted to isolate constituent(s) responsible for antidiabetic activity of the plant. Therefore, it was envisaged to carry out antidiabetic activity-guided-fractionation of bioactive crude fraction of $\mathrm{C}$. indica.

Because of the professed outcome, negligible side effects or toxic contribution and comparatively cost effective than synthetic drugs, herbal, specifically cucurbitaceae family plants are widely advised choice of drug for diabetes even without their scientific backgrounds. However, the scientific record on C. indica plant is very poor. C. indica is the primary choice of plant as a drug in diabetes treatment therefore, the present study was undertaken to evaluate the antidiabetic and hypolipidemic effect.

\section{MATERIALS AND METHODS}

\section{Preparation of plant extract}

The leaves of C.indica were procured locally in rainy season due to ease of availability. The procured leaves were legitimized and confirmed by a Botanist from the Postgraduate Department of Botany, Nagpur University, Nagpur. The said leaves were washed, crushed mechanically and soxhleted with distilled water for $48 \mathrm{hrs}$. The obtained extract was then filtered and carefully concentrated for the purpose of obtaining a semisolid material in a rotating evaporator under reduced pressure. The semisolid material was lyophilized and the resulting powder was stored in an airtight bottle. Insert pictures of the plant and leaves with citations.

\section{Dose}

$200 \mathrm{mg} / \mathrm{kg}$ body wt/day of powder of C. indica dissolved in $5 \mathrm{ml}$ of distilled water.

\section{Selection of animals}

The rats used for the study were Albino Rats. Their weights were in the range of 100-200 grams. All the rats used for the study were kept in the Animal Room of PG Dept. of Biochemistry, LIT, Nagpur. The temperature of the Animal Room was regulated within the range of $24-28^{\circ} \mathrm{C}$. All the rats were maintained on the HL (Hindustan Lever) diet and water as ad libitum during the experimental period. Total rats used were 30 in number and they were divided into 5 groups of 6 animals each.

\section{Induction of diabetes}

Diabetes was induced in the rats using Alloxan Monohydrate.

Five groups of six animals each were created. The animals of group I were given normal controls. The rest of the groups (II, III, IV and V) underwent fasting for 16 hours but they had constant access of water and the diabetes was induced by using the drug Alloxan Monohydrate (18 mg/100 gm body weight) which was administered to them intraperitonially, whereas the rats in group I were given equal amount of saline. As three days had passed after Alloxan Monohydrate was injected, the confirmation of diabetes in the rats of group II was done by estimating levels of plasma glucose. Similarly, the confirmation of hyperlipidemic condition was done correspondingly by estimating serum lipids. The animals in groups III, IV and $\mathrm{V}$ served the purpose of study of drug treatment. The diabetic animals of group III served as alloxan diabetic controls. The diabetic animals of group IV and V were treated with indigenous preparation and oral hypoglycemic drugs. The drug was scheduled for fourteen days.

After the end of experimental period, the animals were denied food for a night and were decapitated at the end of their experimental periods. Blood was collected in fluoride bulbs for estimation of plasma glucose, in plain bulbs for serum estimations and liver was collected for estimation of enzyme activity. Serum from different groups were either analyzed immediately or stored in freezer until they were analyzed for different lipid parameters.

\section{Analytical methods}

Kits were obtained from Ranbaxy and Accurex Biomedical PVT LTD. diagnostic company. 
Plasma glucose ${ }^{15}$, T. cholesterol $^{16}$, Triglyceride ${ }^{17}$, HDLcholesterol $^{18}$, HMG CoA reductase activity (HMG CoA/ Mevalonate ratio) ${ }^{19}$ and LCAT activity (Free cholesterol/ Esterified cholesterol ratio) ${ }^{20}$.

\section{Statistical analysis}

All the data were statistically evaluated and the significance calculated by using student's t test. All the results were expressed as mean $\pm \mathrm{SD}$.

\section{RESULT}

The effect of single dose (200 $\mathrm{mg} / \mathrm{bwt})$ of Coccinia indica for 14 days in alloxan induced diabetic rats showed hypoglycemic and hypolipidemic activity.

The result revealed in Table no 1, that the extract of Coccinia indica had good antidiabetic effect. It showed moderate decrease in the blood glucose, serum cholesterol and triglyceride as compared to other test materials.

The increased VLDL-C and LDL-C levels with decrease in HDL-C concentration in alloxan induced diabetic rats shown significant decreased in VLDL-C and LDL-C with increase in concentration of HDL-C after treatment with C. indica. Thus, this extract is helpful to maintain the lipoprotein concentration in alloxan induced diabetic animals as given in table no. 2 .

Table no. 3 shows the significant improvement in the activity of lipid metabolizing enzymes (HMG CoA reductase and Lecithin cholesterol acyl transferase) after treatment with C. indica in alloxan induced diabetic rats.
Figures 1,2 and 3 shows the efficacy of C. indica with Drug Tolbutamide on glucose, lipids, lipoproteins parameters and lipid metabolizing enzymes (HMG CoA Reductase, LCAT) activity.

\section{DISCUSSION}

The type 2 diabetes is characterized with increased blood glucose level and alteration in lipid and protein metabolism. ${ }^{21-22}$ The prevention and cure related to diagnosis of type 2 diabetes mellitus with new antidiabetic agents and therapies is decidedly dependent on molecular basis of early defects in diabetes mellitus such as beta cell dysfunction, insulin resistance, insulin secretion, excess fatty acid and lipids, obesity and other root cause changes in normal homeostasis. ${ }^{23-24}$ The biochemical estimations were performed to show effects of quercetin present in C. indica on carbohydrate and lipid metabolism.

The traditional system of medicinal plants and practices are seemingly crucial to control various complications of diabetes mellitus in many countries as they are considered to be less toxic and free from side effects as opposed to synthetic molecules. Cucurbitaceae is one of the important families of the plants with potent hypoglycemic effect $^{10,25}$ to be used as the best choice of alternative medicine for treating diabetes throughout India. The current study deals with the plant C. indica for exhibiting antidiabetic activity.

The effectiveness of antidiabetic agents in management of diabetes is judged with measurement of glucose levels in body. ${ }^{26}$

Table 1: Effect of aqueous extract of C. indica on plasma glucose and serum lipids (mg/dl) in alloxan induced diabetic rats

\begin{tabular}{llcc}
\hline Group & Treatment & PI.Glucose & T.Cholestrol \\
\hline Group I & Normal & $85.4 \pm 0.4$ & $90.5 \pm 3.36$ \\
Group II & D. Control & $259.25 \pm 2.09^{\mathrm{c}}$ & $137.8 \pm 3.77^{\mathrm{c}}$ \\
Group III & D. Control & $273.83 \pm 2.51$ & $80.05 \pm 2.83^{\mathrm{d}}$ \\
Group IV & D+C. indica & $94.57 \pm 3.43^{\mathrm{c}}$ & $163.22 \pm 2.84$ \\
Group V & D+Tolbutamide & $120.3 \pm 0.88^{\mathrm{a}}$ & $107.6 \pm 1.31^{\mathrm{d}}$ \\
\hline
\end{tabular}

Values are given as mean $\pm S D(n=6)$. Values were statistically significant at a $(P<0.05), b(P<0.02), c(P<0.01), d(P<0.001)$. Normal vs D. control and Diabetic Control vs Diabetic treated albino rats.

\begin{tabular}{|c|c|c|c|c|}
\hline Group & Treatment & HDL-C & VLDL-C & LDL-C \\
\hline Group I & Normal & $40.38 \pm 0.46$ & $11.48 \pm 0.59$ & $38.14 \pm 2.90$ \\
\hline Group II & D. Control & $35.62 \pm 0.23^{c}$ & $16.0 \pm 0.55^{b}$ & $86.17 \pm 3.96^{d}$ \\
\hline Group III & D. Control & $32.60 \pm 0.07$ & $19.61 \pm 0.18$ & $112.66 \pm 4.87$ \\
\hline Group IV & $D+C$. indica & $39.45 \pm 0.26^{a}$ & $14.12 \pm 0.21^{c}$ & $54.03 \pm 1.33^{a}$ \\
\hline
\end{tabular}

Values are given as mean $\pm S D(n=6)$. Values were statistically significant at a $(P<0.05), b(P<0.02), c(P<0.01), d(P<0.001)$. Normal vs $D$. Control and Diabetic Control vs Diabetic treated albino rats. 


\begin{tabular}{|c|c|c|c|c|c|}
\hline \multirow[t]{2}{*}{ Group } & \multirow[t]{2}{*}{ Treatment } & \multirow[t]{2}{*}{ HMG CoA Reductase } & \multicolumn{3}{|c|}{ LCAT activity (Fc/Ec ratio) } \\
\hline & & & FC & EC & FC/EC \\
\hline Group I & Normal & $1.64 \pm 0.14$ & $22.95 \pm 0.33$ & $67.55 \pm 0.33$ & $0.339 \pm 0.006$ \\
\hline Group II & D. Control & $3.59 \pm 0.16^{d}$ & $38.53 \pm 0.39^{b}$ & $99.27 \pm 0.39^{b}$ & $0.389 \pm 0.005^{b}$ \\
\hline Group III & D. Control & $3.79 \pm 0.12$ & $46.35 \pm 0.13$ & $116.85 \pm 0.15$ & $0.396 \pm 0.001$ \\
\hline Group IV & $\mathrm{D}+\mathrm{C}$. indica & $1.73 \pm 0.13^{c}$ & $28.66 \pm 0.36^{d}$ & $79.1 \pm 0.63^{c}$ & $0.360 \pm 0.001^{c}$ \\
\hline Group V & D+Tolbutamide & $2.04 \pm 0.14^{\mathrm{NS}}$ & $29.46 \pm 0.05^{\mathrm{a}}$ & $80.93 \pm 0.05^{d}$ & $0.364 \pm 0.0008^{a}$ \\
\hline
\end{tabular}

HMG CoA activity mentioned as (HMG CoA/Mevalonate ratio) and LCAT activity mentioned as (FC/EC ratio).Values are given as mean \pm SD ( $\mathrm{n}=6)$. Values were statistically significant at a $(P<0.05), b(P<0.02), c(P<0.01), d(P<0.001)$. Normal Vs D. Control and Diabetic Control Vs Diabetic treated albino rats.

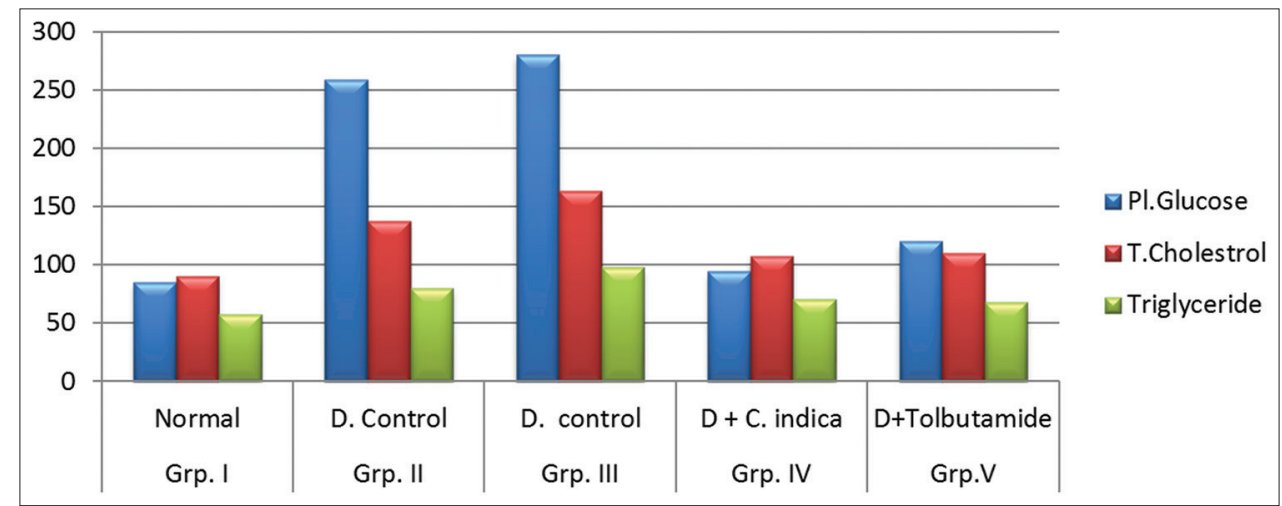

Figure 1: Efficacy of C.indica with Drug on Glucose and lipid.

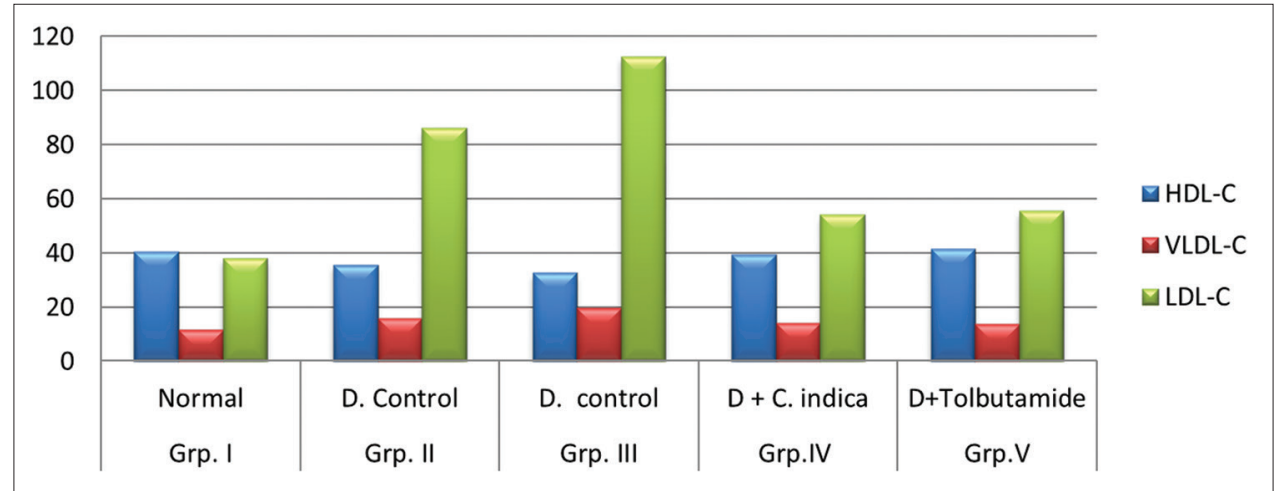

Figure 2: Efficacy of $\mathrm{C}$. indica with Drug on serum Lipoprotein parameters.

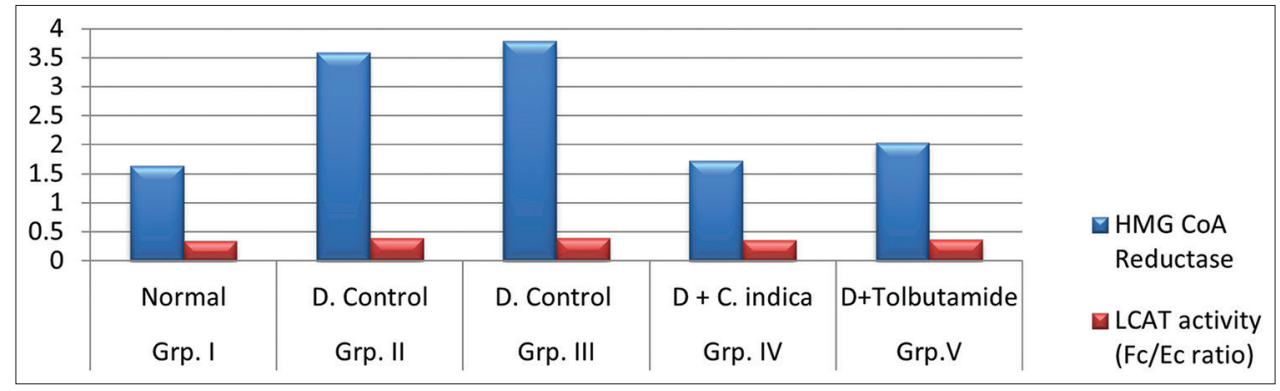

Figure 3: Efficacy of C. indica with Drug on Lipid metabolizing enzymes (HMG CoA reductase, LCAT enzymes) activity.

The concurrent treatment of Coccinia indica for 14 days caused significant reduction $(\mathrm{p}<0.01)$ in blood glucose level in alloxan diabetic rats. Quercetin which is a constituent present in C. indica is responsible for significantly reduced glucose levels compared to diabetic control. Quercetin exhibited a remarkable hypoglycaemic effect similar to metformin. Our results are in agreement with literature reports where quercetin has been reported as an antidiabetic 
agent. ${ }^{27-29}$ Quercetin significantly reduced insulin resistance and increased $\beta$-cell sensitivity in diabetic rats. ${ }^{30-31}$

The malfunctioning of lipids and lipoproteins is associated with type 2 diabetes mellitus and development of insulin resistance. The lipid profile abnormalities in diabetes include elevated levels of Total Cholesterol (TC), Triglycerides (TG), Low Density Lipoprotein (LDL-cholesterol), Very Low Density Lipoprotein (VLDL) and reduced levels of High Density Lipoprotein (HDL-cholesterol). ${ }^{32-33}$ Insulin resistance has prominent effects on size and concentration of lipoproteins (VLDL, LDL and HDL). ${ }^{34}$

Earlier study showed that lipid lowering activity of C. indica might be due to the treatment of active principle quercetin which results in significantly lowered elevated levels of TC, TG, LDL-cholesterol, VLDL and increased HDLcholesterol levels when compared to diabetic control. These results confirm potential of quercetin to reduce risk of cardiovascular disorder and atherosclerosis in diabetes mellitus. These results are in agreement with reports in which quercetin has shown effects such as decrease in serum lipids, improvement of lipid homeostasis and reduction in cardiovascular risk associated with diabetes. ${ }^{35-37}$

The derangements of metabolic processes arising as a result of hyperglycemia induced by insulin insufficiency and the severity of diabetic condition which was indicated by the co-existence of hyperlipidemia and hyperglycemia in disease are often associated with alteration in serum enzymatic activities. Hence the assay of serum enzymes has become an important goal during diabetes.

The existence of cholesterol lowering agents has been demonstrated in different plant species, ${ }^{38,39}$ but their mechanism of cholesterol lowering effects has not been established. In the present study, we have screened aqueous extract of C. indica for its anti- HMG-CoA reductase activity. The decreased HMG CoA reductase activity is probably due to the active ingredients of this plant which affects the absorption of cholesterol in the intestine. The structural similarities to cholesterol might cause the mal-absorption and excretion or might affect the biosynthesis stage of cholesterol in the liver and may lead to cholesterol lowering effect in vivo. ${ }^{40}$

HDL plays a central role in reverse cholesterol transport because it not only promotes the efflux of cholesterol from peripheral tissues but also, it is a major site for the esterification of cholesterol by LCAT. LCAT modulates cholesterol transfer from lipoproteins and cell membrane to HDL. Therefore, the decreased activity of LCAT promotes the accumulation of free cholesterol to cell membrane and of remnant lipoprotein in plasma, both factors being strongly related to Atherosclerosis. ${ }^{41-42}$
The increased level of HDL-cholesterol after administration of C. indica might be due toincrease in the activity of lecithin cholesterol acyl transferase, which may contribute to the regulation of blood lipids.

Our result revealed that $\mathrm{C}$. indica leaves extract caused a significant recovery which might be via stimulating insulin release from $\beta$ cells and hypolipidemic effect of the same is due to active constituents like Quercetin present in C.indica plant (leaves) extract.

\section{CONCLUSION}

From this study we can conclusively state that the extract of C. indica has beneficial effects on blood glucose level as well as rectifying hyperlipidemia due to diabetes. It confirmed that the active principles present in the aqueous extract of $\mathrm{C}$. indica might be responsible for highly significant hypoglycemic and hypolipidemic effect and significant improvement in lipid metabolizing enzyme activity when compared with Drug (Tolbutamide).

The multiple benefits of Coccinia indica shows that it is a true miracle of nature. Numerous studies have been conducted on different parts of Coccinia indica. This plant is yet to be developed as a drug by pharmaceutical industries. A detailed and systematic study is required for identification, cataloguing and documentation of plants, which may provide a meaningful way for the promotion of traditional knowledge of herbal medicinal plants.

\section{REFERENCES}

1. Ananda PK, Kumarappan CT, Sunil C and Kalaichelvan VK. Effect of Biophytum sensitivum on streptozotocin and nicotinamideinduced diabetic rats. Asian Pac J Trop Biomed 2012; 2:31-35.

2. Greenbaum Carla $J$ and Harrison Leonard C. Diabetes: Translating Research into Practice. Informa Health Care, New York, London: 2008; 1-2.

3. Fonseca Vivian A. Clinical Diabetes: Translating Research into Practice. Saunders - An Imprint of Elsevier 2006; 1: 2-3.

4. Ramakrishnamacharya $\mathrm{CH}$, Krishanaswamy MR, Bhima Rao $R$ and Viswanathan S. Anti-inflammatory efficacy of Melothria maderaspatana in active rheumatoid arthritis. Clin Rheumatol 1996; 12:214-215.

5. Harrigan RA, Nathan MS and Beatie P. Oral agents for the treatment of type 2 diabetes mellitus: pharmacology, toxicity, and treatment. Ann Emerg Med 2001; 38:68-78.

6. Lakey WC, Barnard K, Batch BC, Chiswell K, Tasneem A and Green JB. Are current clinical trials in diabetes addressing important issues in diabetes care? Diabetologia 2013; 56:1226-1235.

7. Knowler WC, Barrett-Connor E, Fowler SE, Hamman RF, Lachin JM, Walker EA, et al. Diabetes Prevention Program Research Group. Reduction in the incidence of type 2 diabetes with lifestyle intervention or metformin. $\mathrm{N}$ Engl $\mathrm{J}$ Med 2002;346:393-403. 
8. Taylor John B and Triggle David J. Comprehensive Medicinal Chemistry - II. vol. 1. Elsevier; 2006. (Global Perspective, Text Book); 357.

9. Marles RJ and Farnsworth NR. Antidiabetic plants and their active constituents. Phytomed 1995; 2:137-189.

10. Mohamed B, Abderrahim Z, Hassane M, Abdelhafid T and Abdelkhaleq L. Medicinal plants with potential antidiabetic activity - a review of ten years of herbal medicine research (1990-2000). Int J Diabetes Metabol 2006; 14:1-25.

11. Deokate UAand KhadabadiSS. Pharmacology and phytochemistry of Coccinia indica. Pharmacophore 2012;3(11):179-185.

12. Tailwal P. A marvellous plant-Coccinia indica. European J Biomed Pharm Sci 2016;3:232-238.

13. Anonymous. Database on medicinal plants used in Ayurveda. New Delhi: Central Council for Research in Ayurveda and Siddha 2005.

14. Randhawa K, Kumar D, Jamwal A and Kumar S. Screening of antidepressant activity and estimation of quercetin from Coccinia indica using TLC densitometry. Pharm Biol 2015; 53(12):1867-1874.

15. Trinder P. Determination of glucose in blood using glucose oxidase with an alternative oxygen acceptor. Ann Clin Biochem 1969; 6:24-25.

16. Richmond W. Preparation and properties of a cholesterol oxidase from Nocardia sp and its application to the enzymatic assay of total cholesterol in serum. Clin Chem 1973; 19: 1350-1356.

17. Werner M, Gabrielson DG and Eastman G. Ultramicro determination of serum triglycerides by bioluminescent assay. Clin Chem 1981; 27:268-271.

18. Burstein M, Schoinick HR and Mortin R. Rapid method for the isolation of lipoproteins from human serum by precipitation with polyanions. J Lipid Res 1970; 11: 583-595.

19. Rao $\mathrm{AV}$ and Ramakrishnan S. Indirect Assessment of Hydroxymethylglutaryl-CoA Reductase (NADPH) Activity in Liver Tissue. Clin Chem 1975; 21(10):1523-1525.

20. Obermer E and Milton R. Micro-photometric Method for the Determination of Free Cholesterol and Cholesterol Esters in Blood-Plasma. Biochem J 1933; 27:345-350.

21. Boden $\mathrm{G}$ and Laakso M. Lipids and glucose in type 2 diabetes. Diabetes Care 2004; 27(9):2253-2259.

22. Moller $\mathrm{N}$ and Nair KS. Diabetes and protein metabolism. Diabetes 2008; 57(1):3-4.

23. Leahy JL. Pathogenesis of type 2 diabetes mellitus. Arch Med Res 2005; 36(3):197-209.

24. D'Adamo E and Caprio S. Type 2 Diabetes in youth: epidemiology and pathophysiology. Diabetes Care 2011; 34(Suppliment-2):S161-S165.

25. Ghosh R, Sharatohandra KH, Rita $S$ and Thokchom IS. Hypoglycemic activity of Ficus hispida (bark) in normal and diabetic albino rats. Indian J Pharmacol 2004; 36(4):222-225.

26. Kahn SE. Pathophysiology and treatment of type 2 diabetes: perspectives on the past, present and future. The Lancet 2014; 383(9922):1068-1083.

27. Vessal $M$, Hemmati $M$ and Vasei M. Antidiabetic effects of quercetin in streptozocin-induced diabetic rats. Comp. Biochem Physiol C Toxicol Pharmacol 2003; 135(3):357-364.

28. Mukhopadhyay $P$ and Prajapati AK. Quercetin in anti-diabetic research and strategies for improved quercetin bioavailability using polymer-based carriers - a review. RSC Adv 2015;5(118):97547-97562.

29. Hatware $K$ and Annapurna A. The effect of quercetin on blood glucose levels of normal and streptozotocin induced diabetic (type I and type II) rats. Int J Pharm Chem Biol Sci 2014; 4(3):613-619.

30. Choi HN, Jeong SM, Huh GH and Kim JI. Quercetin ameliorates insulin sensitivity and liver steatosis partly by increasing adiponectin expression in mice. Food Sci Biotechnol 2015; 24(1):273-279.

31. Henagan TM, Lenard NR, Gettys TW and Stewart LK. Dietary quercetin supplementation in mice increases skeletal muscle pgc1a expression, improves mitochondrial function and attenuates insulin resistance in a timespecific manner. PLoS One 2014;9(2):e89365.

32. Peng J, Li Q, Li K, Zhu L, Lin X, Lin X, et al. Quercetin improves glucose and lipid metabolism of diabetic rats: involvement of Akt Signaling and SIRT1. J Diabetes Res 2017;1-10.

33. Yang DK and Kang $\mathrm{H}$. Antidiabetic effect of co-treatment with quercetin and resveratrol in streptozotocin-induced diabetic rats. Biomol Ther 2018;26(2):130-138.

34. Garvey WT, Kwon S, Zheng D, Shaughnessy S, Wallace P and Hutto A. Effects of insulin resistance and type 2 diabetes on lipoprotein subclass particle size and concentration determined by nuclear magnetic resonance. Diabetes 2003; 52(2):453-462.

35. Basarkar PW and Nath N. Hypocholesterolemic and hypolipidemic activity of quercetin-a vitamin P-like compound in rats. Indian J Med Res 1983;77:122-126.

36. Lee KH, Park E, Lee HJ, Kim MO, Cha YJ, Kim JM, et al. Effects of daily quercetin-rich supplementation on cardiometabolic risks in male smokers. Nutr Res Pract 2011;5(1):28-33.

37. Padma VV, Lalitha G, Shirony NP and Baskaran R. Effect of quercetin against lindane induced alterations in the serum and hepatic tissue lipids in Wistar rats. Asian Pac J Trop Biomed 2012; 2(11):910-915.

38. Lee J, Chae K, Ha J, Park BY, Lee HS, Jeong S, Kim MY, Yoon M. Regulation of obesity and lipid disorders by herbal extracts from Morus alba, Melissa officinalis and Artemisia capillaris in high-fat diet-induced obese mice. J. Ethnopharmacol 2008; 115: 263-270.

39. Xie W, Wang W, Su H, Xing D, Cai G and Du L. Hypolipidemic mechanisms of Ananas comosus L. leaves in mice: Different from fibrates but similar to statins. J Pharmacol Sci 2007; 103: 267-274.

40. Ros E. Intestinal absorption of triglyceride and cholesterol. Dietary and pharmacological inhibition to reduce cardiovascular risk. Atherosclerosis 2000; 151: 357-379.

41. Franceschini G, Maderna P and Sirtori CR. Reverse cholesterol transport: physiology and pharmacology. Atherosclerosis 1991; 88: 99-107.

42. Jonas A. Lecithin-cholesterol acyltransferase in the metabolism of high-density lipoproteins. Biochim Biophys Acta 1991; 1084: 205-220.

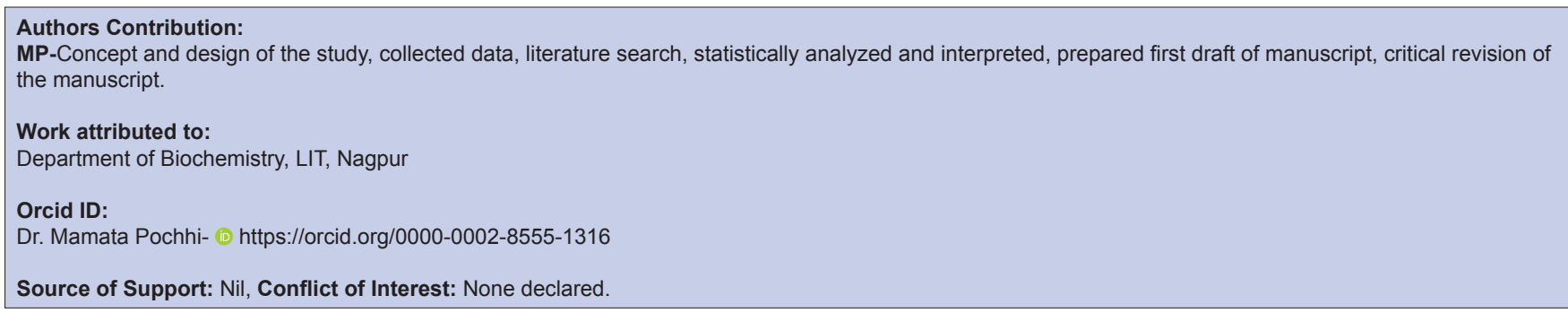

